\title{
A CONSTRUÇÃO \\ DE OBJETOS DE DISCURSO \\ NAS PRÁTICAS \\ CONVERSACIONAIS \\ DE UM GRUPO DE CONVIVÊNCIA \\ DE AFÁSICOS
}

\author{
LA CONSTRUCCIÓN DE OBJETOS DEL DISCURSO EN LAS PRÁCTICAS \\ CONVERSACIONALES DE UN GRUPO DE AFÁSICOS
}

\author{
THE CONSTRUCTION OF OBJECTS OF DISCOURSE IN THE CONVERSATIONAL PRACTICES \\ OF A GROUP OF APHASIC
}

Caio Mira*

Universidade do Vale do Rio dos Sinos

\begin{abstract}
RESUMO: O presente artigo tem como objetivo analisar excertos de uma interação de um grupo de convivência entre afásicos e não afásicos para demonstrar a construção de objetos de discurso em situações conversacionais. Para alcançarmos esse objetivo, a abordagem teórica deste trabalho está baseada na Análise da Conversação de enfoque textual-interativo. Os excertos analisados demonstram que os participantes afásicos do grupo, ao serem inseridos em situações conversacionais, lançam mão de recursos referenciais e interacionais, contribuindo para a construção de objetos de discurso e o gerenciamento do tópico. Os resultados de nossas análises possibilitam evidenciar os aspectos linguístico-interacionais das situações conversacionais do grupo de convivência de afásicos e não somente o déficit linguístico ocasionado pela afasia.
\end{abstract}

PALAVRAS-CHAVE: Afasia. Interação. Objetos de discurso.

RESUMEN: El presente artículo tiene como objetivo analizar fragmentos de una interacción de un grupo de convivencia de afásicos y no afásicos para demostrar la construcción de objetos de discurso en situaciones conversacionales. Para alcanzar este objetivo, el abordaje teórico de este trabajo está basado en el Análisis de la Conversación de enfoque textual-interactivo. Los fragmentos analizados demuestran que los participantes afásicos del grupo, al ser inseridos en situaciones conversacionales, echan mano de recursos referenciales y de interacción, contribuyendo a la construcción de objetos de discurso y a la gerencia del tópico. Los resultados de nuestros análisis ponen en evidencia los aspectos lingüísticos y de interacción de las situaciones conversacionales del grupo de convivencia de afásicos y no solamente el déficit lingüístico ocasionado por la afasia.

*Doutor em Linguística pela Universidade Estadual de Campinas. Docente do Programa de Pós-Graduação em Linguística Aplicadada UniversidadedoValedoRiodos Sinos (Unisinos). E-mail: cmira@unisinos.br. 
PALABRAS CLAVE: Afasia. Interacción. Objetos del discurso.

ABSTRACT: This article aims to analyze excerpts of an interaction between an aphasic group and a non-aphasic group to demonstrate the construction of objects of discourse in conversational situations. To reach that goal, this article's theoretical approach is based on the textual-interactive Conversational Analysis. The analyzed excerpts prove that the aphasic participants of the group, when inserted in conversational situations, dismiss referential and interactional resources, contributing for the construction of objects of discourse and for the management of the topic. The results obtained from the analyses point out to the linguistic-interactional aspects of the conversational situations of the aphasic group, and not only the linguistic deficit caused by aphasia.

KEYWORDS: Aphasia. Interaction. Objects of discourse.

\section{INTRODUÇÃO}

O domínio empírico deste trabalho é a interação, especificamente a conversação face a face, que constitui o cenário básico da aquisição e do uso da linguagem humana (CLARK, 1996). A conversação face a face estabelece e configura "[...] o uso básico e primordial da linguagem, e a melhor descrição para todos os outros usos vem a ser em termos do modo como eles se desviam daquela base" (FILMORE, 1991 apud CLARK, 2000, p. 53). Vale ressaltar que a conversação ocorre no interior de quadros sociais mais explícitos que, ao mesmo tempo, dão forma e conteúdo às ações comunicativas. Partindo dessa premissa, a conversação no âmbito deste trabalho é tomada como uma ação interativa centrada em pelos menos dois interlocutores.

Durante a conversação, há a cooperação mínima para a coerência e a sequencialidade do evento comunicativo. Dessa forma, fatores sociais, cognitivos, contextuais e linguísticos entram em jogo para que haja uma interação bem-sucedida (MARCUSCHI, 1998). Essa definição situa a conversação em um terreno mais amplo, onde a simetria das trocas conversacionais cede espaço à realização de eventos comunicativos, que, por sua vez, ocorrem em função de condições cognitivas, contextuais, sociais e linguísticas essenciais para uma interação.

Se, conforme assinala Marcuschi (1998, p. 7), a conversação “[...] é o exercício prático das potencialidades cognitivas do ser humano em suas relações interpessoais", as práticas conversacionais entre sujeitos afásicos e não afásicos podem constituir um locus privilegiado tanto para a análise da conversação e da sua natureza linguístico-discursiva, quanto também para a observação dos fenômenos sociocognitivos imbricados no entendimento das relações entre linguagem e cognição.

A abordagem sociocognitiva da linguagem considera que os processos cognitivos, entre eles a linguagem, emergem na interação social. Assim, temos uma relação de: mundo - linguagem - mente, pois “[...] as ações verbais são ações conjuntas, ou seja, usar a linguagem é sempre se engajar em alguma ação na qual a linguagem é o meio e o lugar onde a ação acontece necessariamente em coordenação com os outros" (KOCH; CUNHA-LIMA, 2004, p. 285). Nessa perspectiva, a cognição pode ser compreendida como:

[...] situada em dois sentidos: de uma parte, ela pode ser considerada como enraizada na interação social (Rogoff, 1990); de outra parte, ela pode ser compreendida como estando ancorada nos contextos institucionais e culturais diversos (Cole, 1994 et 1995; Wertsch, 1991a et 1991b); a abordagem sociocultural procura reunir esses dois aspectos em um modelo coerente [...]. A atividade, enquanto processo dinâmico situado nas estruturas sócio-históricas, encontra-se assim apresentada como ponto de partida para o estudo do funcionamento mental. Nesses termos, encontra-se ao mesmo tempo estabelecida a concepção de cognição como prática, distribuída, emergente das atividades locais, que não somente se opõe à sua modelização tradicional e individualizante em termos de interioridade e de intencionalidade, mas que, mais geralmente, se recusa à separação entre o que relevaria do domínio do desenvolvimento individual, cognitivo e autônomo, e do que relevaria do domínio da atividade coletiva, interativa e social (MONDADA; PEKAREK, 2000, p. 54-55).

Na abordagem sociocognitiva da linguagem, a referenciação é um fenômeno de natureza semântico-discursiva em que é possível observar a emergência de processos de significação, evidenciando as relações entre linguagem, cognição e interação no contexto das 
afasias. A referenciação representa um deslocamento da clássica questão da referência, por considerar que os processos semânticos não são frutos apenas de uma relação entre as palavras e as coisas, que a construção de referentes no discurso não ocorre somente pela seleção de objetos definidos a priori do uso da linguagem. Pelo contrário, é durante o desenvolvimento da atividade discursiva que emergem os objetos a que o próprio discurso remete. Os "[...] objetos de discurso não preexistem naturalmente à atividade cognitiva e interativa dos sujeitos falantes, mas devem ser concebidos como produtos - fundamentalmente culturais - desta atividade" (APOTHÉLOZ; REICHLER-BÉGUELIN, 1995 apud KOCH, 2005, p. 34). A noção de objetos de discurso rompe com a concepção de a linguagem ser apenas uma forma de nominalizar, de "etiquetar" os objetos no mundo, por situar a linguagem e as atividades de significação como uma atividade cognitiva e social que constitui a realidade humana.

Os objetos de discurso são constituídos na e pela atividade interativa, seja ela por meio de textos escritos, orais ou na conversação face a face, sendo dinâmicos e passíveis de serem (re)configurados semântica e discursivamente. De acordo com Mondada (1994 apud KOCH, 2004, p. 79), o objeto de discurso

[...] caracteriza-se pelo fato de construir progressivamente uma configuração, enriquecendo-se com novos aspectos e propriedades, suprimindo aspectos anteriores ou ignorando outros possíveis, que ele pode associar com outros objetos ao integrar-se em novas configurações, bem como articular em partes suscetíveis de se autonomizarem por sua vez em novos objetos. O objeto se completa discursivamente.

Diante do domínio empírico constituído pela conversação e o deslocamento da noção de referência sob a perspectiva sociocognitiva, pretendemos demonstrar as atividades referenciais desempenhadas para a construção de objetos de discurso e a manipulação do tópico discursivo nas práticas de linguagem de um grupo de convivência de afásicos.

\section{AFASIAS}

As afasias são, fundamentalmente, sequelas de um acidente vascular cerebral, de traumatismos cranianos ou de tumores cerebrais que afetam sensivelmente a linguagem em seus vários níveis de constituição e processamento. As afasias podem afetar as formas de articulação e produção dos segmentos fonético-fonólogicos, a capacidade de ordenar sintaticamente os elementos dos enunciados, a seleção de itens lexicais em situações comunicativas, os processos semânticos de compreensão e produção (JAKOBSON, 1954; LURIA, 1981).

Essa concepção de afasia está fundamentada em uma idealização de um normal da linguagem, sendo os testes metalinguísticos e descontextualizados o terreno propício para a consolidação de uma tradição no campo da Afasiologia. As baterias de testes ${ }^{1}$ possibilitam diagnosticar e classificar os tipos de afasia e suas diferentes correlações anátomo-clínicas. Os testes consistem em tarefas essencialmente metalinguísticas, buscando mensurar o (re)conhecimento da língua a partir de procedimentos como: repetição de fonemas, palavras e sentenças; denominação de objetos; definição de palavras; fazer sentenças com palavras especificadas pelo examinador; completar frases; explicação de provérbios; leitura em voz alta e silenciosa; cópia de palavras e parágrafos; ditados de palavras e frases; fala e escrita espontâneas (COUDRY, 1988).

Nesse contexto, as manifestações afásicas em nada teriam a ver com processos que também ocorrem na linguagem não patológica; além disso, são diagnosticadas a partir de testes de base estruturalista e normativa que têm o pressuposto de que elas são, essencialmente, um problema da ordem de uma metalinguagem estrita, ou seja, um problema de reconhecimento das estruturas e das propriedades da língua tomada como um sistema fechado em si mesmo. Morato (2001, p. 22) sintetiza este posicionamento que por muito tempo norteou os estudos afasiológicos:

\footnotetext{
${ }^{1}$ No escopo do presente texto, os testes não serão discutidos ou comparados com os dados de interação de afásicos. O nosso objetivo é apresentar um panorama de uma concepção tradicional de afasia amparada em uma dicotomia normal versus patológico que toma como princípio o conhecimento metalinguístico para o diagnóstico e a classificação das afasias.
} 
A afasia tem sido definida tradicionalmente como um problema metalinguístico conforme postula Jakobson (1954/1981): “a afasia pode ser definida amiúde como um problema relativo às operações metalinguísticas”. Isso quer dizer que o que estaria afetado nas afasias diz respeito fundamentalmente a um conhecimento metalinguístico do mundo. Procedimento recorrente para o estudo, a descrição de sua semiologia e a conceituação tradicional das afasias, as baterias de testes-padrão, prenhes de tarefas metalinguísticas quase caricaturais com relação às propriedades da língua "Tornou-se clássico perturbam a metalinguagem. Isso porque falar uma língua (e fazê-lo adequadamente) estaria subordinado à capacidade (lógico-perceptiva, bem entendido) de falar sobre esta língua. (...) perder-se-ia nas afasias não apenas a capacidade de falar sobre a linguagem, mas essa possibilidade de reflexividade da linguagem que consiste numa reação de reparação e de reconstituição de processos linguísticos".

Conceber as afasias como um problema de metalinguagem (aqui reduzida ao metalinguístico) e de perda da capacidade de reflexão de seu uso instiga-nos a refletir a respeito da seguinte questão: seriam as afasias, que dizem respeito à linguagem e a todo tipo de processo afeito a ela, somente um problema de ordem metalinguística?

Estudos representativos sobre afasia, realizados do Brasil, já responderam a essa questão ao demonstrarem que a afasia é uma perturbação da atividade discursiva com impactos no exercício da/sobre a linguagem em relação ao(s) outro(s) e ao mundo, portanto, uma questão de linguagem que abrange seu estatuto enunciativo, interativo, semântico, referencial e sociocognitivo (cf. COUDRY, 1988; 2002; MORATO, 2000; MORATO et al., 2012).

Portanto, consideramos que a afasia não é só um problema de reconhecer e operar as unidades linguísticas, mas, também, um problema de ordem discursiva, interacional e sociocognitiva, pois há um quadro de instabilidades provocado por um evento neurológico e suas implicações vão além das sequelas neurocognitivas, atingindo a capacidade de se comunicar e impactando de forma significativa nas atividades da vida cotidiana.

\section{O TÓPICO DISCURSIVO}

A concepção da noção do tópico, calcada inicialmente no âmbito gramatical da frase, passando para a abordagem funcionalista e posteriormente para o domínio discursivo, aponta para a delimitação da forma do tópico ou, melhor dizendo, para a configuração de uma categoria de análise. Na realidade, a indagação de Brown e Yale (1983) a respeito do caráter intuitivo da noção de tópico traduz a dificuldade de operar uma categoria de análise no plano empírico do discurso, isto é, na materialidade linguística de textos orais e escritos. A saída alternativa ao intuitivismo que cerca a noção de tópico na perspectiva anglo-saxônica do discurso é fixar parâmetros analíticos na relevância daquilo que é falado num determinado ponto discursivo.

Por outro lado, a abordagem de Maynard (1980) enfoca a função que o tópico tem na interação, ou seja, no caráter interativo que o tópico exerce para a organização do discurso, sobretudo, em interações orais. O contraste perceptível na definição da noção de tópico demonstra uma tensão entre a forma que o tópico tem (a partir de qual critério é delimitado) e sua função (o papel que essa categoria exerce). A tensão entre essas duas faces da noção de tópico discursivo é atenuada de maneira satisfatória para fins teóricoanalíticos a partir da integração da forma e da função do tópico: o enfoque textual-interativo.

Os estudos brasileiros realizados no âmbito do Projeto da Gramática do Português Falado (PGPF), projeto resultante de um grande empreendimento que congregou pesquisadores renomados para a elaboração de uma gramática de referência do português falado no Brasil, agregam à noção de tópico o viés de uma categoria textual-interativa. Dessa forma, a noção de tópico passa a ter um caráter eminentemente discursivo, pois se manifesta, na conversa, por meio de "[...] enunciados formulados pelos interlocutores a respeito de um conjunto de referentes explícitos ou inferíveis, concernentes entre si e em relevância num determinado momento da construção partilhada da interação oral" (KOCH; URBANO; JUBRAN, 1992, p. 386).

No âmbito da perspectiva textual-interativa, é fundamental que o produto linguístico seja abordado a partir das marcas que os fatores interacionais imprimem na superfície textual (JUBRAN, 2006a). A abordagem textual-interativa conforme é desenvolvida

Mira | A construção de objetos de discurso nas práticas conversacionais de um grupo de convivência de afásicos 
nos estudos da PGPF, particularmente preconizada por Jubran (2006b), apresenta uma tendência em atribuir um maior peso na dimensão textual do que na dimensão interativa para conceituação do tópico como uma categoria analítica. A autora justifica tal posicionamento em função "[...] do estabelecimento de traços que definam uma categoria analítica operacionalizável com alguma segurança e objetividade na identificação de unidades textuais" (JUBRAN, 2006b, p. 91). Especificamente, o peso interacional do enfoque de tópico discursivo denomina o envolvimento conjunto dos interlocutores na produção de um texto e não como o fator de demarcação tópica.

A opção de dar maior ênfase ao caráter textual do tópico, isto é, direcionar a análise para as marcas textuais salientes nas situações conversacionais, minimiza o intuitivismo do analista para delimitação dos pontos de formação tópica em textos orais. Esse posicionamento, tal como é defendido por Jubran (2006b), resulta em uma maior segurança metodológica na etapa de análise do nosso corpus. Outra justificativa para a ênfase da dimensão textual recai justamente nas propriedades que definem a noção de tópico como uma categoria analítica. São duas as suas propriedades, segundo a autora: centração e organicidade.

A propriedade de centração assume um papel fundamental para definição de tópico, pois é por meio dela que é possível identificar na dinamicidade da conversa os referentes textuais mais recorrentes que compõem um conjunto de semelhanças temáticas. Para isso, a propriedade da centração abrange três traços: a concernência, a relevância e a pontualização. A especificidade de cada um dos traços na propriedade da centração é a seguinte:

a) concernência: relação de interdependência semântica entre os enunciados de um segmento textual implicativa, associativa, exemplificativa ou de outra ordem, pela qual se dá a integração desses enunciados em um conjunto específico de referentes (objetos de discurso);

b) relevância: proeminência desse conjunto decorrente da posição focal assumida pelos seus elementos;

c) pontualização: localização desse conjunto, tido como focal em determinado momento do texto falado (JUBRAN, 2006b, p. 92, grifos nossos).

Os traços da propriedade de centração visam delinear o tópico em sua materialidade textual, ou seja, apreender o conjunto de referentes dispostos na superfície do texto que apresentem entre si uma dada simetria temática. A propriedade de centração e seus traços são os instrumentos que permitem identificar com maior clareza (de forma menos intuitiva) o tema ou o assunto que emerge na conversação, estando relacionada à dimensão textual da noção de tópico discursivo. Jubran (2006a) salienta que a concernência e a relevância são os traços imprescindíveis para precisar a centração tópica, enquanto a pontualização é o traço que permite localizar os limites de um segmento tópico num determinado momento da conversa.

Já a segunda propriedade da noção de tópico, a organicidade, diz respeito às relações de dependência tanto no plano intratópico quanto no plano intertópico. É a propriedade de organicidade que permite estabelecer a abrangência dos tópicos. A organicidade abrange $o$

a) plano hierárquico conforme as dependências de super-ordenação e sub-ordenação entre tópicos que se implicam pelo grau de abrangência do assunto;

b) no plano linear, de acordo com as articulações intertópicas em termos de adjacência ou interposições de tópicos diferentes na linha do discurso (JUBRAN, 2006b, p. 94).

O plano hierárquico configura uma relação de ordenação dos tópicos, uma relação vertical em que um tópico maior se ramifica em tópicos menores em função da abrangência referencial e temática. A organização hierárquica é o que permite ao analista formar os “quadros tópicos” (QT). As condições necessárias para a elaboração de um QT, segundo Jubran (2006b, p. 96), são: “[...] a centração mais abrangente e focal de um tópico (supertópico - ST), numa porção maior do texto; a divisão desse ST em tópicos coconstituintes (subtópicos - SbT)”. A respeito da relação de interdependência tópica no nível vertical, a autora menciona que no âmbito das 
pesquisas do Grupo da PGPF foi enfatizado inicialmente que a organização dos tópicos ocorria por meio de relações intertópicas, porém, tal constatação foi revista em análises posteriores.

A organização tópica também ocorre num plano linear, pois "[...] os segmentos tópicos, tomados individualmente, deixam transparecer uma estruturação interna, através de marcas constatadas no início, meio e fim dos segmentos" (KOCH; URBANO; JUBRAN, 1992, p. 392). As marcas de estruturação internas indicam a organização intratópica, isto é, o plano linear da organicidade. As relações entre os tópicos na linearidade discursiva ocorrem por meio de dois fenômenos: a continuidade e a descontinuidade. A continuidade decorre da organização sequencial dos tópicos - quando a abertura de um tópico ocorre após o fechamento de outro. No outro extremo, a descontinuidade ocorre em três casos: (i) pela suspensão definitiva de um tópico, quando a inserção de um novo tópico implica no encerramento de um tópico antecedente; (ii) pela cisão de tópico em partes que se apresentam de forma não-adjacente; (iii) pela expansão posterior de um tópico apenas anunciado anteriormente (JUBRAN, 2006b). Os mecanismos da organização intratópica manifestam-se em algumas estratégias de construção textual, das quais podemos destacar os processos referenciais mobilizados na construção dos objetos de discurso.

\section{PROCEDIMENTOS METODOLÓGICOS}

O fragmento do episódio conversacional que analisamos neste trabalho é proveniente do acervo de dados linguísticos-interacionais do Grupo de Pesquisa Cognição, Interação e Significação ${ }^{2}$ (COGITES). Esse acervo consiste em gravações em meio audiovisual das interações ocorridas no Centro de Convivência de Afásicos, o CCA. Atualmente, o acervo conta com cerca de 450 horas de interação gravadas em vídeo, 350 horas digitalizadas e 200 horas transcritas.

Diante do amplo acervo de dados do COGITES, os critérios que nortearam a escolha dos excertos do episódio conversacional analisados no presente trabalho foram os seguintes: a configuração do grupo durante os encontros ocorridos em um ano; a recorrência de atividades de linguagem que fossem representativas do enquadre interacional Relato do Cotidiano e a recorrência de encontros em que os participantes afásicos apresentam maior engajamento na atividade do Programa de Linguagem e desenvolvimento do tópico. Os maiores detalhes acerca da configuração interacional do CCA e de suas atividades são esclarecidos a seguir.

O CCA foi concebido como um espaço de interação para o exercício efetivo de práticas cotidianas de linguagem entre os participantes afásicos e não afásicos a fim de contribuir para o maior entendimento da condição de afásico e oferecer alternativas para a reintegração social pela convivência e enfrentamento mútuo das inúmeras dificuldades que a afasia implica. Além disso, o CCA também é um espaço de pesquisa e de docência onde pesquisadores e alunos de pós-graduação desenvolvem pesquisas que abrangem a complexa relação entre os aspectos sociais e interativos que envolvem linguagem, cérebro e cognição. Os participantes af́sicos que frequentam o CCA são encaminhados pelo Departamento de Neurologia, onde recebem todo tipo de assistência clínica necessária. Os não afásicos que integram o CCA são amigos, familiares e pesquisadores, sendo que estes últimos desenvolvem seus trabalhos no Instituto de Estudos da Linguagem da UNICAMP (MORATO et al., 2002, MIRA, 2007; 2012).

A fim de desmedicalizar as afasias, o espaço físico que abriga o CCA fica nas dependências físicas do IEL, localizado dentro do campus, estando a manutenção física e econômica do CCA sob a responsabilidade do IEL e da UNICAMP. Assim, apesar dos membros já terem um histórico consolidado de interações, persistem algumas convenções sociais e padrões de comportamentos relacionados a esse caráter institucional local do CCA. Tal aspecto encontra-se refletido de algum modo nas interações, agindo mesmo na organização da conversação (MIRA, 2007).

Os encontros desse grupo do CCA acontecem semanalmente, às quintas-feiras, em um prédio especialmente adaptado para tal finalidade, situado nas dependências do Instituto de Estudos da Linguagem da Universidade Estadual de Campinas

\footnotetext{
${ }^{2}$ O grupo de pesquisa COGITES - Cognição, Interação e Significação -, que reúne pesquisadores de diferentes formações, dedica-se ao estudo das relações entre linguagem e cognição por meio da descrição e análise de práticas discursivas, em especial as que envolvem indivíduos com afasia e com Doença de Alzheimer. Disponível em: <http://cogites.iel.unicamp.br>.
} 
(IEL/UNICAMP). As atividades do grupo são iniciadas, geralmente, às nove horas, estendendo-se até aproximadamente ao meio dia, desdobrando-se em duas partes principais, mediadas por uma pausa para o café preparado coletivamente: o Programa de Expressão Teatral e o Programa de Linguagem. No presente trabalho, os dois excertos analisados são do Programa de Linguagem.

As atividades do Programa de Linguagem procuram explorar os diversos gêneros e eventos que constituem o uso da linguagem no cotidiano, tais como: diálogos, comentários, narrativas, a exposição, a discussão de notícias de jornais e revistas, as discussões sobre temas sociais e culturais diversos (principalmente de produções culturais como filmes, peças de teatro e obras literárias), comentários sobre o noticiário e a vida política do país, assim como também relatos da vida cotidiana e familiar dos membros do grupo. Em outras palavras, tais atividades constituem um espaço marcado por um conjunto de rituais sociais, pelo fortalecimento dos quadros interativos, nos quais os participantes podem enfrentar suas dificuldades linguístico-cognitivas e estabelecer processos alternativos de significação, pela evocação de inúmeras práticas de linguagem (CAMERIN, 2005).

Na realidade, tais atividades são situações concretas de práticas de linguagem. Longe da formalidade de outros tipos de intervenção com objetivos de natureza médica ou fonoaudiológica, o Programa de Linguagem busca evocar contextos de interação verbal que, na maioria das vezes, não fazem mais parte do cotidiano dos afásicos. O regaste de situações que desencadeiam a conversação, considerada um dos pilares da vida social, promove, além do exercício das habilidades linguísticas, a reatualização dos elos sociais e cooperativos inerentes às rotinas humanas. Esse é o principal diferencial das atividades de linguagem promovidas no/pelo CCA em relação a grupoterapias tradicionais, que via de regra visam à normalização das formas linguísticas e aos comportamentos padronizados (MIRA, 2012).

As atividades do Programa de Linguagem configuram-se como um evento interativo reunião. O evento interativo reunião pressupõe o direcionamento das atividades por um dos integrantes e a existência de uma pauta que organiza a ação. Durante o desenvolvimento das atividades do Programa de Linguagem, observamos a emergência do enquadre interativo Relatos do Cotidiano. O conceito de enquadre interativo refere-se à percepção de qual tipo de situação interativa ocorre durante a conversação, de qual o sentido negociado conjuntamente pelos falantes na interação (TANNEN; WALLAT, 1987/2002, p. 188-189).

Os participantes de uma interação são capazes de perceber as alterações nas estruturas de participação que provocam a emergência de novos enquadres interativos. A consequência da emergência de novos enquadres interativos é a modificação da dinâmica dos turnos e das formas de desenvolvimento do tópico.

As formas de desenvolvimento do tópico dizem respeito a quem o instaura e o conduz mediante a estrutura de participação vigente. Esses dois fatores estão atrelados ao tipo de enquadre interativo que se estabelece durante a reunião. A emergência dos enquadres e a alteração na estrutura de participação e na forma de desenvolvimento do tópico afetam sensivelmente o engajamento dos participantes afásicos nas atividades do Programa de Linguagem do CCA.

Especificamente, os excertos apresentados neste artigo são oriundos do enquadre Relatos do Cotidiano. Nesse enquadre interativo, é requerido que os participantes elaborem relatos ou teçam comentários a respeito de algum tópico surgido na discussão ou durante o desenrolar de alguma atividade específica na qual o grupo esteja envolvido, sendo caracterizado fundamentalmente por uma flexibilidade da estrutura de participação. Dessa forma, o sistema de trocas de turno é mais irregular, há mais sobreposições e o desenvolvimento do tópico ocorre de maneira menos dirigida.

O enfoque textual-interativo será utilizado em nossas análises para contemplar o gerenciamento do tópico discursivo e a construção de objetos de discurso. A escolha do enfoque textual-interativo é justificada em função da colaboração entre os interlocutores na interação oral, o partilhar de conhecimento entre ambos e o esforço e a disposição para produzir inferências e negociar os sentidos (KOCH; PENNA, 2006).

O sistema de notação utilizado na transcrição dos dados tem como base as notações já utilizadas nos estudos do projeto NURC e marcações propostas por Marcuschi (1998) para a análise de interações orais, acrescidas de alguns elementos que salientam aspectos importantes para a análise das situações interativas envolvendo indivíduos afásicos, como a presença de semioses não-verbais

Fórum linguistic., Florianópolis, v. 13, n.2, p.1131-1146,abr./jun.2016. 
(aspectos proxêmicos, expressão facial, atitudes corporais, gestualidade, direcionamento do olhar etc.), fundamentais para a compreensão da dinâmica interativa das atividades do CCA (MORATO et al.; 2005). Para garantir a melhor compreensão dos dados, adotamos alguns procedimentos que valem ser ressaltados:

a) a identificação dos participantes do CCA é feita a partir das iniciais do nome e do sobrenome;

b) o texto da transcrição é apresentado em sistema ortográfico modificado, conforme o sistema de notação de transcrição (cf. sistema de notação em anexo);

c) no caso de locução, são usadas as iniciais em letras maiúsculas dos participantes; quando se trata de suas condutas não-verbais ou de significação não-verbal, a descrição de tais aspectos segue entre parênteses.

\section{PERFIL DOS PARTICIPANTES AFÁSICOS}

\section{$5.1 \mathrm{EF}$}

EF é um senhor natural de Uauá (BA), nascido em setembro de 1942, casado e pai de três filhos. Reside há muitos anos em Campinas. Seu grau de escolaridade é superior, tendo feito o curso de Direito. Hipertenso, em 21/12/1988 apresentou queda súbita, com perda de consciência, tendo sido encaminhado ao Hospital de Clínicas da UNICAMP. Observou-se hemiplegia à direita com predomínio em membro superior direito e alteração de consciência, decorrentes de um Acidente Vascular Cerebral isquêmico de origem embólica.

Sua linguagem espontânea, segundo informações de seu prontuário hospitalar, foi reduzida a estereotipias ("não, não”; “au-au”), utilizada em praticamente todas as situações comunicativas. Identificaram-se também alterações práxicas envolvendo os níveis lingual, labial e sub-glótico, que o impediam de executar movimentos voluntários sob comando. O diagnóstico neurológico inicial foi "afasia de Broca, predominantemente eferente".

A produção oral de EF caracteriza-se por emissão de palavras isoladas, apresentando o que na literatura afasiológica é chamado de "estilo telegráfico". A articulação da fala é laboriosa, gerando sequências ininteligíveis e, por vezes, criando segmentos que não pertencem ao inventário fonológico da língua portuguesa. Muitas vezes, EF necessita de prompting oral para produzir os itens lexicais que deseja pronunciar, recorrendo frequentemente à escrita como apoio para comunicar o que deseja ou para dar a entender os sentidos que produz.

Apesar do severo comprometimento de sua produção verbal, EF participa ativamente das discussões do grupo. Não são raras as ocasiões em que as inserções de EF, realizadas por meio de elementos não verbais, contribuem significativamente para o desenvolvimento do tópico. EF também produz vocalizações e algumas palavras curtas durante o turno de outros participantes, $o$ que funciona como sobreposições de turno, demonstrando seu engajamento nas interações do grupo.

Nas ocasiões em que EF não consegue se comunicar verbalmente, ele usa gestos faciais e expressão corporal, além de utilizar a escrita e desenhos para tornar compreensível e relevante seu envolvimento nas atividades. EF participa do CCA desde 1990 e tem uma relação de boa convivência e familiaridade com os demais integrantes do grupo.

\section{$5.2 \mathrm{JM}$}

JM é um senhor brasileiro, destro, casado, nascido em março de 1933 na cidade de São Paulo (SP). Em 17/11/2000, JM foi acometido por um Acidente Vascular Cerebral (AVC) à esquerda, apresentando dificuldade na fala e alteração do movimento do lado esquerdo

\footnotetext{
${ }^{3}$ A hemiplegia consiste em um tipo de paralisia cerebral que compromete seriamente um dos lados do corpo (RAPP, 2001).

${ }^{4}$ Os integrantes do CCA utilizam frequentemente os promptings orais no intuito de dar continuidade ao desenvolvimento do tópico e também do turno. O prompting oral é a pista articulatória, ou seja, é a execução, pelo interlocutor, do primeiro gesto articulatório ou das primeiras sequências do gesto que compõem as primeiras sílabas da palavra pretendida (Freitas, 1997).
} 
do rosto. De acordo com o exame neurológico realizado no Hospital de Clínicas da UNICAMP em 23/09/2002, JM apresentou inicialmente um quadro de afasia semântica. Também apresenta dificuldades fono-articulatórias, produzindo parafasias fonológicas e semânticas, embora consiga comunicar-se de forma razoavelmente satisfatória. JM demonstra estar integrado aos acontecimentos e fatos noticiados pela imprensa. Sempre participa das discussões agregando novas informações sobre os tópicos debatidos nas atividades de linguagem. Residindo em São Paulo, sua frequência no CCA não é muito constante. O senhor JM participa do CCA desde 2001.

\section{$5.3 \mathrm{MN}$}

MN é uma senhora portuguesa, destra, dona de casa, nascida em setembro de 1927. Em 26/06/1999, apresentou uma forte dor de cabeça e hemiparesia à direita completa, sendo em seguida encaminhada para o Hospital de Clínicas da UNICAMP. De acordo com o exame neurológico, $\mathrm{MN}$ apresentou um quadro de afasia transitória decorrente de infarto cerebral na região da cápsula interna à esquerda, cujos traços proeminentes são uma hemiparesia à direita, dificuldade de evocar palavras (Word-finding-difficulty) e produção de parafasias semânticas.

Assídua e engajada nas reuniões do grupo, $\mathrm{MN}$, contudo, expressa sempre que possível um grande descontentamento em relação à sua condição de afásica, sendo comuns seus lamentos e reclamações frente às limitações diárias impostas pela afasia. No entanto, apesar de demonstrar tal descontentamento, MN participa das atividades de forma engajada realizando sobreposições ao turno dos outros participantes para se posicionar em relação ao tópico e para agregar informações em relação ao que se discute ou planeja. Integra o CCA desde 2002.

\section{$5.4 \mathrm{SP}$}

SP é um senhor nascido em março de 1933, de origem italiana que, aos dois meses de idade, mudou-se para o sul da França, tendo se naturalizado francês. Aos 36 anos, sofreu um Acidente Vascular Cerebral isquêmico (afetando a área do lobo temporal e núcleo da base parcialmente), que o deixou com uma afasia expressiva e com uma hemiplegia à direita, diagnosticadas no Hospital de Clínicas da UNICAMP. Sofreu novo AVC cerca de 30 anos depois, o que agravou seu quadro afásico.

De acordo com os dados obtidos em entrevista anamnésica, SP tem o francês como língua materna, embora os pais fossem italianos. Passou a praticar o português aos 20 anos, quando veio para o Brasil junto com a família, apesar de já ter tido contato com a língua portuguesa por influência de seu pai, que morara por algum tempo no país. Ainda que após o AVC SP tenha recuperado parcialmente sua capacidade de expressão e compreensão do francês, é o português a língua por meio da qual ele mais se comunica (com esposa, amigos e outros integrantes do CCA).

Quando fala o português, a afasia de SP é compatível com as formas essenciais das afasias ditas motoras ou expressivas: dificuldades de evocação, hesitações e prolongamentos, dificuldades de repetição, perseverações ${ }^{6}$ e parafasias ${ }^{7}$ verbais e fonológicas. No francês, embora suas dificuldades sejam menores e sua desenvoltura mais perceptível, observa-se a presença do mesmo conjunto de características semiológicas.

Nas interações do CCA, SP participa ativamente das discussões do grupo, verbal e gestualmente, opinando sobre os fatos debatidos. Frequentemente, realiza sobreposições ao turno dos outros participantes para se posicionar em relação ao tópico e para agregar informações à discussão. Os recursos mais utilizados por ele para compensar o seu déficit linguístico incluem o uso de gestos de natureza indexical e vocalizações que servem para contornar as dificuldades de processamento lexical. SP demonstra ter uma grande integração com os outros participantes e é membro assíduo do CCA desde 1992.

\footnotetext{
${ }^{5}$ Paralisia muscular que atinge um dos lados do corpo, geralmente o lado contrário ao do local da lesão cerebral (RAPP, 2001).

${ }^{6}$ Tendência de repetir o mesmo enunciado verbal em resposta aos diferentes estímulos.

${ }^{7}$ Parafasia, basicamente, diz respeito à substituição de uma palavra-alvo (aquela pretendida pelo sujeito) por uma outra ou da troca de um som por outro, podendo variar o grau de semelhança entre o som ou palavra pretendidos e os efetivamente realizados (RAPP, 2011).
} 


\section{ANÁLISE DE UMA SITUAÇÃO CONVERSACIONAL}

No Programa de Linguagem, os participantes afásicos MN, JM, SP e EF, juntamente com HM e EM, participantes não afásicas, estavam engajados em uma atividade coletiva que consistia em comentários a respeito de atualidades a partir da leitura de manchetes de um jornal. Nessa ocasião, os integrantes escolhiam uma notícia e discutiam os desdobramentos dos fatos. Essa discussão era colaborativa e a manchete jornalística servia como desencadeador do tópico conversacional, mobilizando o conhecimento de diversas naturezas: das atualidades, do mundo, das formas de interação e dos recursos interacionais compartilhados pelo grupo, tais como respeito às pausas mais extensas, hesitações, alongamentos vocálicos e promptings

Nos dois excertos transcritos abaixo, a participante EM comentava algumas notícias selecionadas durante o encontro e solicitava que os demais integrantes escolhessem uma para ser discutida pelo grupo. Era a partir desse contexto que ocorriam o desenvolvimento tópico e os fenômenos referenciais dessa interação.

\section{Excerto 1}

Linhas: 1-15

1 EM: olha gente...eu li aqui...abri o jornal hoje...quer dizer sim bom...vou

aqui selecionar um notícia para levar lá...de cara...o que foi que eu li aqui de

cara...dá umas espiadas dona N...lê alto para p grupo se quiser

$2 \mathrm{MN}$ : ler

3 EM: é justamente esta aqui pessoal

4 MN: desemprego atinge dezenove oito...por cento em São Paulo

5 EM: li isto aqui e falei ai meu Deus...primeira notícia que li...

$6 \mathrm{JM}: \quad$ [quase vinte

7 EM: vinte por cento...desemprego atinge vinte por cento das pessoas em São

Paulo

8 JM: pessoas...pessoas... são

9 EM: [de quando....sei lá...quantas pessoas têm

10 JM: não...diga...diga...trabadoree: : :s)

11 EM: $\quad[$ a cidade de São Paulo

12 JM: é exatamente re: : : : gião de São Paulo

13 EM: tem quantas pessoas em São Paulo...sei lá...umas dez milhões...a

cidade... imagina só toda a região 15 das cidades perto de São Paulo...não sei se

falo uma loucura é muita gente né

14 JM: é no perto as pessoas trabalo Sã: : : o Paulo é Brasil

15 EM: é...aí eu falei assim...eu pensei assim...essa notícia tá muito ruim vou

ler outra notícia...aí eu li essa aqui

A manchete jornalística, lida por MN (linha 4) instaura o tópico desenvolvido ao longo do excerto 2: o alto índice do desemprego em São Paulo. Apesar do excerto 2 não apresentar desdobramentos que afetam o desenvolvimento do tópico, como, por exemplo, subtópicos, rupturas, cisão ou maiores expansões, é interessante observar como o referente do tópico é construído coletivamente pelo grupo como um objeto de discurso. O referente desemprego em São Paulo é recategorizado durante o desenvolvimento tópico.

A leitura da manchete, realizada por MN, apresenta um índice quantitativo expressivo que produz um efeito argumentativo importante no desenvolvimento tópico. O índice 19,8\% de desemprego, que foi retomado na fala de JM (linha 6) como quase vinte, é parte integrante de um conjunto referencial que institui a coesão entre os enunciados, conferindo o traço da concernência da propriedade da centração tópica (JUBRAN, 2006b, p. 93). Ao retomar o referente desemprego pelo índice de vinte por cento, a centração tópica é desencadeada pela presença de lexemas do mesmo campo conceitual que é ativado na leitura da manchete (dezenove oito, pessoas, trabadorees, São Paulo, região, Brasil). Consideramos que a fala de JM da linha 6 é o elemento coesivo que ao mesmo tempo retoma o referente desemprego e serve como âncora na retomada de outros referentes que compõem um recorte semântico e interativo a respeito do desemprego. No momento em que JM enuncia que o índice chega a quase vinte por cento, ocorre uma retomada que recategoriza o referente, promovendo a especificação do tópico e a construção de um objeto de discurso negociado ao longo da interação. 
A construção do objeto de discurso foi iniciada a partir da fala de JM, na linha 6, que é ratificada por EM na linha 7. Inicialmente, a notícia expressava: desemprego atinge 19,8\% em São Paulo, conforme foi lida por MN. Ainda que a recategorização de 19,8\% para 20\% não represente diferenças significativas no aspecto quantitativo no índice de desemprego, é possível perceber algumas sutis diferenças semânticas da construção do objeto de discurso no âmbito da interação. O objeto trazido a priori por uma manchete de jornal, o índice do desemprego é coconstruído na interação ao ser desdobrado nas seguintes dimensões: quantidade e abrangência.

Na linha 7, a expressão nominal vinte por cento das pessoas em São Paulo marca não só a especificação do índice do desemprego, mas também a categorização desse objeto discursivo. Se na leitura da manchete o objeto de discurso instaurado no tópico é marcado por um índice quantitativo, a retomada por essa expressão nominal o interativo atribui marcas de predicação e o categoriza. Na linha 10, JM explicitamente recategoriza o objeto de discurso para uma especificidade diretamente relacionada ao desemprego, inserindo no desenvolvimento desse segmento tópico o referente trabadorees.

As expressões nominais pessoas e trabadoorees categorizam e recategorizam respectivamente o referente desemprego, sendo elementos fundamentais na referenciação e no desenvolvimento do tópico. A importância das expressões nominais nesse processo é defendida por Koch (2008), que argumenta que a categorização/recategorização do objeto de discurso por meio de não ocorre somente na dimensão temática do enunciado nos movimentos de introdução, retomadas e remissões. Segundo a autora, as expressões nominais são responsáveis pelo acréscimo de informações novas ao tema e pela sequenciação do discurso.

A abrangência do desemprego é um referente que é rotulado de diferentes formas no decorrer deste episódio conversacional. A manchete aponta que o desemprego atinge São Paulo, sem especificar se é a cidade, a região metropolitana ou o estado todo. Essa especificação que rotula o referente desemprego é discutida pelos interactantes e atribui uma predicação significativa, ajustando o saber disponível a respeito do objeto de discurso (MARCUSCHI; KOCH, 2006). O segmento 7-14 apresenta o referente São Paulo, que é recategorizado e recebe um rótulo metonímico: São Paulo é Brasil, conforme o enunciado de JM na linha 14.

\section{Excerto 2}

\section{Linhas: $17-44$}

17 EM: leia alto por favor seu M

18 JM: aliados...se re: :velam...e...ameaçam o governo

19 EM: aliados se revelam e ameaçam o governo...ai meu Deus do céu...outra notícia...dura

20 SP: é bem lá...na...na...no Paraná...Paraná...o caminhão

21 HM: caminhão desculpa

22 SP: o caminhão... pa-rado..para...o

23 HM: Paranaguá

24 SP: o caminhão

26 JM: [de soja

27 HM: Paranaguá né...

28 SP: tá (numa)

29 HM: greve

30 EM: uma greve

31 SP: [ô:: : : :

32 EM:..o senhor tá falando das notícias né...procurando uma notícia

hoje...melhor...então a gente viu o quê seu

$33 \mathrm{HM}$ :

[melhorzinha

34 EM: E...essa aqui do desemprego...depois a greve dos portuários lá em... no

Paraná...falamos sobre o governo que está acuado pela...oposição...

35 EF: san...santo

36 EM: Santos...em greve também?

37 JM: também

38 HM: ah mais pelos menos

39 EM: tô por fora

40 EF: santo

41 EM: O senhor falou Santos eu entendi

42 EF: soja

43 HM: ah da soja 
44 EM: soja...ah que é exportada pelo porto de Santos...é...também tem...né ((JM aponta para o jornal que está nas mãos de EM)) ...olha acho que notícia boa mesmo é o seguinte o Brasil vai ganhar do Paraguai ((risos))

No segundo excerto, dando continuidade às atividades do Programa de Linguagem, EM solicita a leitura aleatória de mais uma manchete por JM. O tópico instaurado pela leitura da manchete diz respeito às ameaças dos aliados políticos ao governo. Apesar do dado não apresentar maiores detalhamentos da notícia, e, consequentemente, os desdobramentos do tópico que levam SP, nas linhas 20 e 22, a inserir o referente caminhão, que instaura uma nova cadeia referencial (caminhão, parado, soja, Paranaguá, greve, santo, porto). A partir desse referente é possível observar no excerto fenômenos inferenciais ancorados no texto que possibilitam a ativação de novos referentes na construção discursiva do objeto inserido pela manchete jornalística, uma função exercida pelas anáforas indiretas $(\mathrm{AI})$.

Segundo Marcuschi (2005), a definição das AI é complexa, pois demanda um alargamento da noção mais tradicional de anáfora, em que um terno retoma outro numa relação direta de correferencialidade. Conforme explica o autor, baseado em Schwarz (2000), a AI tem duas funções: a introdução de novos referentes e a continuação da relação referencial global. No caso das AI, não ocorre uma retomada direta de referentes, mas sim uma ativação de novos referentes com uma motivação e ancoragem no universo textual.

De acordo com a concepção de AI defendida por Marcuschi (2005), o referente caminhão configura-se, no âmbito da interação, como uma âncora textual que ativa novos referentes que constroem um objeto discursivo. Isso pode ser observado na linha 26 , no enunciado de JM, em que há uma primeira inferência sobre o referente caminhão que colabora no que tange à progressão tópica, à discussão da manchete jornalística e à coesão interacional das inferências que ocorrem na sequência do episódio conversacional. No segmento 26-29, podemos observar como essas inferências configuram novos referentes que são desencadeados por caminhão. As linhas 26 e 27 trazem, respectivamente, soja e Paranaguá na centração do tópico greve e no estabelecimento desse objeto de discurso, que fica evidente na linha 34 .

A continuação da relação referencial global da AI pode ser observada no segmento 35-44, iniciado pelo enunciado de EF, um participante acometido por uma afasia severa, que retoma à primeira vista, no âmbito interacional, o tópico greve. No entanto, esse enunciado reativa uma cadeia referencial mencionada anteriormente: caminhão, parado, soja, Paranaguá. Especificamente, o enunciado da linha 35 (san...santo) confere a continuidade do objeto de discurso que é desenvolvido nesse episódio conversacional e ilustra o traço da concernência da propriedade da centração tópica (JUBRAN, 2006a). O enunciado de EM, na linha 44, assinala o percurso interacional na construção do objeto de discurso e o esgotamento do tópico nos dois excertos analisados neste trabalho.

\section{CONSIDERAÇÕES FINAIS}

O intuito das análises dos dois excertos selecionados foi demonstrar as formas de construção de objetos de discurso em um contexto muito peculiar: as situações conversacionais de grupo de convivência de afásicos e não afásicos. A especificidade desse tipo de dado conversacional nos permite tecer algumas considerações pertinentes em relação às práticas conversacionais nas afasias, sobretudo em relação às características dos participantes afásicos no contexto do CCA, e às noções de tópico e de objeto de discurso que estão imbrincadas no plano textual-interativo da conversação.

Os afásicos do grupo, ao estarem inseridos em situações conversacionais, lançam mão de recursos referenciais e interacionais, contribuindo para o desenvolvimento do tópico discursivo e a construção de objetos de discurso. Um olhar mais atento para as práticas conversacionais dos afásicos possibilita abordar como foco nos recursos referenciais que entram em jogo na cena interativa, em situações de conversação. Cabe ressaltar que nossos excertos expressam um momento de uma situação conversacional, portanto, um exemplo de como a linguagem afásica pode ser observada por meio de uma ótica que leva em conta não só os déficits linguísticos, mas também o que é preservado, retrabalhado e o reconhecimento de aspectos semânticos e pragmáticos necessários para a conversação. 
Não é possível deixar de mencionar que, no âmbito deste trabalho, o tipo e grau de severidade da afasia, o tempo de pertencimento do grupo e sua especificidade são fatores que influem diretamente nas formas da interação, porém, não são aspectos definidores que impedem ou limitam a participação nas práticas conversacionais e, consequentemente, no desenvolvimento do tópico e das estratégias referenciais. A presença de pausas mais extensas, hesitações, dificuldades de articulação fonético/fonológica não impedem ou são fatores limitadores para o engajamento dos afásicos no fluxo conversacional e no desenvolvimento do tópico de objetos de discurso.

Mesmo apresentando excertos de um único momento interativo, os resultados apresentados neste trabalho pretendem desvencilhar a afasia de uma mera questão de desordem mental ou metalinguística por meio da evidência dos aspectos linguístico-interacionais das situações conversacionais do grupo de convivência de afásicos. Fenômenos similares aos que foram analisados em nossos dados são recorrentes em outras interações do grupo de convivência de afásicos. No entanto, em função da questão do espaço de nosso trabalho não é possível apresentar mais exemplos de outras interações, seja no interior do CCA ou de outas pessoas acometidas por diferentes tipos de afasia em diferentes situações conversacionais. Nosso intuito foi apresentar excertos prototípicos que possibilitam a compreensão dos fenômenos textuais-interativos elencados no âmbito desse artigo, considerando a especificidade do espaço de convivência que é proporcionado pelo CCA.

Por fim, pretendemos lançar, a partir de nossas análises, uma reflexão acerca do tópico e dos objetos de discurso, que são duas noções imbrincadas nos processos sociocognitivos de construção e interpretação de sentidos que ocorrem na interação. Conforme é salientado por Pinheiro (2012), embora tópico discursivo e objetos de discurso sejam duas noções linguisticamente distintas, no jogo interacional elas não se separam, pois são expressões referenciais que configuram e reconfiguram o tópico no texto/discurso. Dessa forma, para a análise de textos conversacionais, é necessário um olhar do analista que considere a simbiose dessas duas noções para os fenômenos semânticos e textuais que ocorrem no curso das interações face a face, sobretudo nos contextos de conversação em grupo, que são domínios empíricos complexos e heterogêneos.

\section{REFERÊNCIAS}

BROWN. G.; YULE, G. Discourse analysis. Cambridge: Cambridge University Press, 1983.

CAMERIN, I. P. D. Discurso quotidiano no CCA/IEL Unicamp. 2005. 102 f. Dissertação (Mestrado em Linguística) - Instituto de Estudo da Linguagem, Universidade Estadual de Campinas, Campinas, 2005.

CLARK, H. Using language. Cambridge: Cambridge University Press, 1996.

. O uso da linguagem. Cadernos de Tradução, Porto Alegre, v. 3, n. 9, p. 49-71, jan./jun. 2000.

COUDRY, M. I. H. Diário de Narciso: Discurso e afasia. São Paulo: Martins Fontes, 1988.

. Linguagem e afasia: uma abordagem discursiva da neolinguística. Cadernos de Estudos Linguísticos, Campinas, v. 42, n.42, p. 99-129, 2002.

FREITAS, M. Alterações fono-articulatórias das afasias motoras: um estudo linguístico. 1997. 262 f. Tese (Doutorado em Linguística) - Instituto de Estudos da Linguagem, Universidade Estadual de Campinas, Campinas, 1997.

JAKOBSON, R. Linguística e comunicação. São Paulo: Cultrix, 1954/1981.

JUBRAN. C. C. Revisitando a noção de tópico discursivo. Cadernos de Estudos Linguísticos, Campinas, v. 48, n.1, p. 33-44, 2006a. 
O tópico discursivo. In: JUBRAN. C.C.A.; KOCH. I. G. V. (Org.). Gramática do português falado culto no Brasil: a construção do texto falado. Campinas: Editora da Unicamp, 2006b. p. 89-132.

KOCH, I. G. V.; URBANO, H.; JUBRAN, C. C. A. Organização tópica da conversação. In: ILARI, R. (Org.). Gramática do português falado: níveis de análise linguística. Campinas: Editora da Unicamp/Fapesp,1992. p. 32-49.

KOCH. I. G. V.; PENNA, M. A. O. Construção e Reconstrução de objetos-de-discurso: manutenção tópica e progressão textual. Cadernos de Estudos Linguísticos. Campinas, v. 48, n.1, p. 23-31, 2006.

Como se constroem e reconstroem os objetos do discurso. Investigações, Pernambuco, v. 21, n. 2, p. 99-114, 2008.

KOCH, I. G. V. Introdução à linguística textual. São Paulo: Martins Fontes, 2004.

; CUNHA-LIMA, M. L. Do cognitivismo ao sociocognitivismo. In: MUSSALIN, F.; BENTES, A. C. (Org.). Introdução à linguística: fundamentos epistemológicos. São Paulo: Cortez, 2004. p. 251-300.

Referenciação e orientação argumentativa. In: BENTES, A, C.; KOCH, I. G. V.; MORATO, E. M. (Org.). Referenciação e discurso. São Paulo: Cortez, 2005. p. 33-52.

LURIA, A. R. Basic problems of neurolinguistcs. The Hague: Mouton, 1976.

Fundamentos de neuropsicologia. São Paulo: EDUSP, 1981.

MARCUSCHI. L. A. Análise da conversação. São Paulo: Ática, 1998.

; KOCH, I. G. V. Referenciação. In: JUBRAN. C. C. A.; KOCH.I.G.V. (Org.). Gramática do português falado culto no Brasil: a construção do texto falado. Campinas: Editora da Unicamp, 2006b. p. 381-402.

. Anáfora indireta: o barco textual e suas âncoras. In: BENTES, A. C.; KOCH, I.V. \& MORATO, E. M. (Org.). Referenciação e discurso. São Paulo: Cortez, 2005. p. 103-122.

MAYNARD, D. Placement of topic changes in conversation. Semiotica, v. 30, n. 3/4, p. 263-290, jul./dez. 1980.

MIRA, C.C.C.R. O CCA como uma comunidade práticas: uma análise das interações do Centro de Convivência de Afásicos. 2007. 107 f. Dissertação (Mestrado em Linguística) - Instituto de Estudos da Linguagem, Universidade Estadual de Campinas, Campinas, 2007.

. Afasia e interação: uma análise da dinâmica de turnos e da gestão do tópico nas práticas conversacionais de sujeitos afásicos e não-afásicos. 2012. 166 f. Tese (Doutorado em Linguística) - Instituto de Estudos da Linguagem, Universidade Estadual de Campinas, Campinas, 2012.

MONDADA. L.; PEKAREK, S. Interaction sociale et cognition située: quels modèles pour la recherche sur l'acquisition des langues? AILE, v. 12, n. 4, p. 147-17, 2000.

MORATO, E. M. As afasias entre o normal e o patológico: da questão (neuro)linguística à questão social. In: SILVA, F. L; MOURA. H. M. (Org.). Direito à fala: a questão do preconceito linguístico. Florianópolis: Insular, 2000. p. 85-95.

Neurolinguística. In: MUSSALIM. F.; BENTES. A. C. (Org). Introdução à linguística: domínios e fronteiras. 2 vol. São Paulo: Cortez, 2001.p. 143-170. 
et al. Sobre as afasias e os afásicos: subsídios teóricos e práticos elaborados pelo Centro de Convivência de Afásicos. Campinas: Editora da Unicamp, 2002.

et al. Análise da competência pragmático-discursiva de sujeitos afásicos que frequentam o Centro de Convivência de Afásicos (CCA-IEL/UNICAMP). Relatório Final de Pesquisa Processo FAPESP 03/02604-9. Departamento de Linguística Instituto de Estudos da Linguagem, Universidade Estadual de Campinas, 2005.

et al. Processos implícitos, contextuais e multimodais na construção referencial em conversações entre afásicos e não afásicos: relato de pesquisa. Linguagem em (Dis)curso, Tubarão, v. 12, p. 711-742, 2012.

PINHEIRO, C. P. Objeto de discurso: sistematizando relações. Linguagem em (Dis)curso, Tubarão, v.12, n.3, p. 793-813, 2012.

RAPP, B. The hanbook of cognitive neuropsychology: what deficits reveal about the human mind. Philadelphia: Psychology Press, 2001.

TANNEN. D; WALLAT. C. Enquadres interativos e esquemas de conhecimento em interação: exemplos de um exame/consulta médica. In: RIBEIRO, B. T.; GARCEZ, P. M. Sociolinguística Interacional. 2. ed. São Paulo: Loyola, 2002. p. 182-196. 
ANEXO A - SISTEMA DE NOTAÇÃO DA TRANSCRIÇÃO

\begin{tabular}{|c|c|c|}
\hline OCORRENCIAS & SINAIS & EXEMPLOS \\
\hline $\begin{array}{l}\text { Incompreensão de palavras ou } \\
\text { segmentos }\end{array}$ & $(\mathrm{SI})$ & $\begin{array}{c}\text { Então é...olha deve ta com }(\mathrm{SI}) \ldots \text { deixa eu } \\
\qquad \text { ver... }\end{array}$ \\
\hline Hipótese do que se ouviu & (hipótese) & Aqui (livro)...ah \\
\hline Truncamento ou interrupção brusca & l & Dia pri/trinta e um de julho \\
\hline Entonação enfática & Maiúscula & afaSIAS \\
\hline Prolongamento de vogal e consoante & $\begin{array}{c}\text { : (podendo aumentar de acordo com a } \\
\text { duração }\end{array}$ & Agora...a:...a Ida Maria que pesquisou \\
\hline Silabação & - & Ser-vi-do-res \\
\hline Interrogação & $?$ & Pra quem você mandou isso? \\
\hline Qualquer pausa & $\ldots$ & Ela veio qui... perguntar... veio se instruir \\
\hline $\begin{array}{c}\text { Pausas prolongadas (medidas em } \\
\text { segundos) }\end{array}$ & $(4 s)$ & $\begin{array}{l}\text { MS: ã.:.:.ham (3s) centro } \\
\text { indica } 5 \text { segundos de pausa }\end{array}$ \\
\hline $\begin{array}{c}\text { Comentários do transcritor e } \\
\text { designações gestuais }\end{array}$ & $(($ minúscula $))$ & Isso não... ((risos) $)$ \\
\hline $\begin{array}{c}\text { Comentários que quebram a seqüência } \\
\text { temática da exposição }\end{array}$ & -- & $\begin{array}{l}\text { Maria Éster... - . dá pra... ta longe aí né... } \\
\text { pequenininho... eu também não enxergo } \\
\text { direito...-Oliveira da Silva... e ela também } \\
\text { é coordenadora }\end{array}$ \\
\hline Superposição & $\begin{array}{l}\text { [ apontando o local onde ocorre a } \\
\text { superposição }\end{array}$ & $\begin{array}{l}\text { MG: Nova Iguaçu } \\
\text { [JM: } \quad \text { ah }\end{array}$ \\
\hline Simultaneidade de vozes & $\begin{array}{l}\text { [ } \text { apontando o local onde ocorre a } \\
\text { simultaneidade }\end{array}$ & $\begin{array}{c}\text { MN: [[ eu falava.. mas } \\
\text { NS: [[ quatro ano.. deixa } \\
\text { (indica que duas conversas ocorrem } \\
\text { simultaneamente) }\end{array}$ \\
\hline Indicação de que a fala foi retomada & ... no início & $\begin{array}{c}\text { EM: a gente ta mandando pros } \\
\text { coordenadores e eles tão colocando onde... } \\
\text { EM: ...nas bibliotecas... }\end{array}$ \\
\hline Citações literais ou leituras de textos & “” & $\begin{array}{c}\text { aqui... “vimos por meio dessa... desta } \\
\text { agradecer o envio dos livros...” }\end{array}$ \\
\hline $\begin{array}{c}\text { Indicação e continuidade } \\
\text { de gestos significativos, com a descrição } \\
\text { de gestos }\end{array}$ & $\begin{array}{l}\text { * início e fim do gesto }{ }^{*} \\
\text { continuidade gestual }\end{array}$ & $\begin{array}{l}\text { NS: i::xi... faz tempo aqui } \\
\text { ((aponta com o dedo)) }\end{array}$ \\
\hline
\end{tabular}

Fonte: Morato et al. (2005) 